change who did not have a skeletal survey performed but would have qualified under the new guidelines.

Conclusions Implementing Wood's criteria increased the number of skeletal surveys performed threefold. Given the high yield of additional fractures found, we would encourage others to consider adopting this policy for skeletal survey in children under two to reduce the chance of missing occult fractures. Our experience demonstrates that such a policy is workable in a busy district general hospital.

\section{G156(P) TOWARDS THE BARNAHUS (CHILD HOUSE) MULTI- AGENCY MODEL OF CARE FOR CHILD SEXUAL ABUSE: THE VALUE OF A FAMILY THERAPIST AND A YOUNG PERSON ADVOCATE}

'S Rodrigues, ${ }^{1} \mathrm{M}$ Wong, ${ }^{2} \mathrm{~A}$ Weedon, ${ }^{3} \mathrm{~S}$ Qasir, ${ }^{1} \mathrm{~A}$ Benson, ${ }^{1} \mathrm{D}$ Hodes. 'Paediatrics, University College London Hospital, London, UK; ${ }^{2}$ Young Person Advocate, Solace Women's Aid, London, UK; ${ }^{3}$ Family Therapy, Tavistock and Portman NHS Trust, London, UK

\subsection{6/archdischild-2018-rcpch.152}

Background Lack of appropriate support following sexual abuse can lead to long-term emotional, physical and social problems. The Child House will be launched in 2018. As a first step, a Child/Young Person Advocate (CA) and a Family Therapist (FT) joined the Paediatrician in an established clinic for the assessment of historic child sexual abuse.

Objectives To determine the value of integrated psychosocial and advocacy services in the clinic.

Method A retrospective review of notes for 20 patients before integration (BI), compared with 22 patients after integration (AI) was carried out. Outcome measures included emotional and behavioural needs and referrals.

Results In the BI versus A1 cohort, 8 (40\%) had emotional problems and $3(15 \%)$ were in police proceedings versus 12 $(55 \%)$ and $3(13 \%)$ respectively.

Only two patients were referred to their local Mental Health Service before integration.

In the AI cohort, 10 patients had the FT in the paediatric consultation and one had a further appointment in a week, five in two or more weeks and four were referred to another FT for psychological support. Two made a new disclosure in the clinic and were referred to social care.

Six patients had the CA present at the paediatric consultation for support with the court process and one had an appointment later. One parent was referred for domestic violence support.
Conclusions This study showed having the FT and CA join the consultation provided 17 of $22(78 \%)$ patients, immediate or early management for mental health needs and police proceedings. A multidisciplinary team supports the varied needs of our patients and is at the centre of the Barnahus model. Future research will review the child and parent opinion about this model and also the outcomes for the child.

\section{G157(P) THE SIGNIFICANCE OF INJURY COMBINATIONS IN CHILDREN REFERRED FOR A FORENSIC MEDICAL EXAMINATION}

A Christmas. Centre for Forensic and Legal Medicine, University of Dundee, Dundee, UK

\subsection{6/archdischild-2018-rcpch. 153}

Objectives The significance of injuries in combination in physical child abuse is generally not well documented. This study investigated whether the presence of multiple injury types is suggestive of abuse, and considered whether external injuries can predict internal ones.

Methods Records of paediatric forensic medical examinations from 2011 to mid-2016 were retrospectively reviewed. Details of injuries were recorded, including type, number, and location. Additional cases involving fractures were identified from 2009-2010 records. Cases were classified as 'abuse', 'accidental' or 'inconclusive', and data compared.

Results Applying $\chi_{2}$ testing, there was a statistically significant difference $(\mathrm{p}<0.05)$ between the proportion of abused (66.04\%) and accidentally injured (37.50\%) children who had multiple types of 'standard' injury. Abused children were significantly more likely to have multiple injury types in the same body region than accidentally injured $(52.83 \%$ vs $20.83 \%)$. The proportion of abused and accidentally injured children with co-existing bruises and abrasions did not differ significantly; however, abused children were significantly more likely to have spatially related bruises and abrasions.

Only $1 / 58$ abusive fractures had overlying bruising; however, 7/9 abused children with fractures had bruising elsewhere. 2/2 children with accidental fractures had overlying swelling, compared to $2 / 9$ abused (table 1 ).

Conclusions The presence of multiple injury types in children referred for forensic medicine examinations may suggest abuse, especially if at least one body region contains different injury types. However, these findings are not completely sensitive for, or specific to, abuse. External injuries appear to poorly predict internal.

\begin{tabular}{|c|c|c|c|c|c|c|}
\hline & $\begin{array}{l}\text { Physical abuse } \\
(\mathrm{n}=106)\end{array}$ & $\begin{array}{l}\text { Accidental injury } \\
(n=24)\end{array}$ & $\begin{array}{l}\text { Inconclusive } \\
(n=58)\end{array}$ & $\begin{array}{l}P \text { value: abuse vs } \\
\text { accident }\end{array}$ & $\begin{array}{l}P \text { value: abuse vs } \\
\text { inconclusive }\end{array}$ & $\begin{array}{l}P \text { value: accident vs } \\
\text { inconclusive }\end{array}$ \\
\hline Children with Multiple Injury Types (\%) & $70(66.04)$ & $9(37.50)$ & $35(60.34)$ & 0.010 & 0.468 & 0.059 \\
\hline $\begin{array}{l}\text { Children with Multiple Injury Types (same body } \\
\text { region) (\%) }\end{array}$ & $56(52.83)$ & $5(20.83)$ & $24(41.38)$ & 0.005 & 0.161 & 0.077 \\
\hline $\begin{array}{l}\text { Children with Bruise and Abrasion (anywhere) } \\
\text { (\%) }\end{array}$ & $61(57.58)$ & $9(37.50)$ & $29(50.00)$ & 0.075 & 0.353 & 0.302 \\
\hline $\begin{array}{l}\text { Children with Bruise and Abrasion (same body } \\
\text { region) (\%) }\end{array}$ & $47(44.30)$ & $5(20.83)$ & $21(36.21)$ & 0.034 & 0.312 & 0.173 \\
\hline
\end{tabular}

